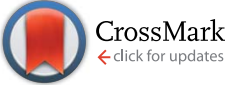

Cite this: RSC Adv., 2016, 6, 78970
Received 23rd June 2016 Accepted 13th August 2016 DOI: $10.1039 / c 6 r a 16254 a$ www.rsc.org/advances

\section{Impact of PEGylation and non-ionic surfactants on the physical stability of the therapeutic protein filgrastim (G-CSF)}

\begin{abstract}
Patrick K. Chang, Clive A. Prestidge, Timothy J. Barnes and Kristen E. Bremmell*
Improvement in the in vitro and in vivo stability of biotherapeutic proteins has been approached via a number of strategies, including protein PEGylation or formulation with non-ionic surfactants. Here we report on interaction and stability studies for the biotherapeutic protein filgrastim (granulocyte stimulating factor (G-CSF)) and its PEGylated analogue (PEG-GCSF), with polysorbate 20, using isothermal calorimetry, circular dichroism, surface tension and dynamic light scattering measurements. PEGylation of G-CSF did not alter temperature-induced conformational changes detected with circular dichroism, however did increase the amphiphilic nature of G-CSF, lowering the surface tension to a greater extent. G-CSF and PEG-GCSF both aggregated at temperatures below that of denaturation. GCSF had an inverse relationship between concentration and the temperature at which aggregation was initiated, with aggregates continually increasing in size to greater than $2 \mu \mathrm{m}$. Importantly, PEG-GCSF was shown to have improved resistance to heat-induced aggregation; the presence of PEG attached to the protein minimised the aggregate size to below $120 \mathrm{~nm}$. Interaction between polysorbate 20 and the proteins was weak and determined to result from a hydrophobic mechanism. A two-site binding model was found to best describe the interaction of polysorbate 20 with G-CSF, irrespective of PEGylation. Presence of polysorbate 20 did not minimise the thermal-induced instability for G-CSF or PEG-GCSF. These findings provide new insight into the mechanism of therapeutic protein stabilization using PEG and non-ionic surfactants.
\end{abstract}

\section{Introduction}

Therapeutic proteins offer distinct advantages over other small drug molecules, such as having a specific mechanism of action, high potency, and bioactivity even at low therapeutic concentrations. As a result, these molecules have become one of the fastest growing classes of therapeutic molecules on the market. ${ }^{\mathbf{1 , 2}}$ The native protein $3 \mathrm{D}$ conformation is a product of its specific amino acid sequence and the presence of secondary structures such as $\alpha$-helices and $\beta$-sheets. Due to the inherent structure-activity relationship of proteins, successfully maintaining the specific conformation is critically important during their production, transportation and storage.

One approach to address formulation stability of the native protein conformation and potential for adsorption or aggregation has been to formulate bio-therapeutics with non-ionic surfactants. Their role in stabilising therapeutic protein formulations has not been well established, due in some part to the protein dependent nature of the mechanism. A number of studies have investigated the effect of non-ionic surfactants, in

School of Pharmacy and Medical Sciences, Sansom Research Institute, University of South Australia, Adelaide, South Australia 5000, Australia. E-mail: Kristen. bremmell@unisa.edu.au; Tel: +61883022311 particular polysorbates, on therapeutic protein stability and also on the interaction between polysorbates and proteins. Both the influence on stability and the binding of polysorbates to proteins has been demonstrated to be dependent on the type of protein. Non-ionic surfactants have been shown to interact with proteins by acting as a chemical chaperone, binding to the protein and preventing protein aggregation and adsorption to surfaces, as encountered during transportation and storage of proteins where agitation and exposed interfaces may induce aggregation., ${ }^{3,4}$ Surfactant molecules may bind to exposed hydrophobic patches present on the surface of the protein molecule ${ }^{5-7}$ and have been shown to favour refolding of protein over self-induced aggregation by binding transiently with partially unfolded proteins. $^{3,8}$ Above the critical micelle concentration (CMC), the presence of surfactant micelles may aid in protection of proteins by encapsulating the protein within the micelle, which prevents self-induced aggregation or interaction between protein molecules with hydrophobic interfaces. ${ }^{1}$ Preferential adsorption of surfactant at air-solution and solution-solid interfaces, preventing protein adsorption, denaturation and aggregation at these interfaces has also been proposed. ${ }^{9}$

Protein conjugation with polyethylene glycol (PEG), a water soluble, biocompatible polymer is now a well-established 
method to enhance the in vivo circulation lifetime and reduce the frequency of dosing required for protein therapeutics, with a number of PEGylated proteins on the market. ${ }^{10,11}$ Biological activity and circulation time of PEGylated proteins have been reported extensively in literature, with fewer studies reporting on formulation and stability. Conjugation of the hydrated PEG chain results in an increased molecular volume, contributing to the longer circulation time and consequently impacting on some of the biophysical properties of the protein. Most studies have reported the secondary and tertiary structure to be independent of PEGylation. ${ }^{12,13}$ In terms of stability in solution, the conformation and aggregation of proteins has been demonstrated to depend on both the PEG conjugation strategy and the protein. Protein stability in solution has been demonstrated to increase for various PEGylated proteins; for example, PEG-GCSF exhibited a reduced rate and extent of aggregate formation compared to its non-PEGylated form, while retaining a similar aggregation pathway, ${ }^{14}$ and the thermal stability human growth hormone was increased dependent on the conjugation method..$^{15}$ PEGylated lysozyme was also found to have lower propensity toward aggregate formation compared to native lysozyme. ${ }^{16}$

Granulocyte Colony Stimulating Factor (G-CSF) is a cytokine that regulates the proliferation and differentiation of neutrophilic granulocytes, possessing functional activities on granulocytes and monocyte-macrophages. ${ }^{17,18}$ Recombinant G-CSF has been marketed for clinical use in enhancing hematopoietic recovery after cancer chemotherapy and bone marrow transplantation. ${ }^{19,20}$ Expressed from Escherichia coli (E. coli), GCSF is a non-glycosylated protein consisting of 175 amino acid residues with a molecular weight of $18.8 \mathrm{kDa}$. The sequence of this isolated protein is structurally identical to the sequence of G-CSF isolated from human blood, except for the presence of methionine at the N-terminal residue, necessary for both expression in E. coli, as well as for chemical conjugation of polyethylene-glycol (PEG). ${ }^{21}$ PEG-GCSF exhibits comparable clinical outcomes to G-CSF, with a reduced dosing cycle as a result of its long circulation half-life. ${ }^{11}$ While PEGylated protein therapeutics are formulated with non-ionic surfactants, similarly to non-PEGylated analogues, few studies have considered the impact of non-ionic surfactants on the physical stability of PEGylated proteins. Treuheit et al. ${ }^{22}$ reported increased thermal degradation of PEG-GCSF with increased concentration of polysorbate 20 over a 59 week study, however for agitation induced aggregation, increased polysorbate 20 concentrations decreased the aggregation.

In this study, we investigated both the impact of PEGylation on biophysical stability aspects of G-CSF, and the interaction of the non-ionic surfactant, polysorbate 20, with G-CSF and PEGGCSF. Circular dichroism (CD) was used to provide information on conformational changes with respect to PEGylation and in the presence of polysorbate 20. Surface tension measurements were used to probe the influence of PEGylation on G-CSF adsorption to the air-water interface, providing knowledge on the amphiphilic nature of the proteins. Isothermal titration calorimetry (ITC) was used to investigate the nature of binding between surfactant and protein, and dynamic light scattering was used to monitor protein aggregation as a function of temperature. This provides important insight into protein formulation and stability using PEGylation and non-ionic surfactants.

\section{Materials and methods}

\subsection{Materials}

Pharmaceutical grade human recombinant Granulocyte Colony Stimulating Factor (G-CSF), PEGylated Granulocyte Colony Stimulating Factor (PEG-GCSF) and pure polysorbate 20 used in this study were provided by Hospira. Inc, Adelaide. The G-CSF component is a small globular protein $(\sim 18800$ Da) composed of $4 \alpha$-helices and 2 disulfide bonds. The PEG was a $20 \mathrm{kDa}$ mPEG chain covalently attached to the $\mathrm{N}$ terminus of G-CSF. The proteins were obtained as stock solutions in $10 \mathrm{mM}$ sodium acetate buffer at $\mathrm{pH}$ 4, with G-CSF and PEG-GCSF concentration of $3.5 \mathrm{mg} \mathrm{ml}^{-1}$ and $10 \mathrm{mg} \mathrm{ml}^{-1}$, respectively. Acetic acid, Glacial (AR grade) was obtained from Ajax Chemicals and sodium acetate salt purchased from Sigma (Australia). Milli-Q water was used throughout.

\subsection{Methods}

2.2.1. Circular dichroism. The far-ultra violet circular dichroism (UV CD) spectra of G-CSF and PEG-GCSF in the absence or presence of varying concentration of polysorbate 20 were recorded on a JASCO-815 spectropolarimeter (JASCO International Co. Ltd., Hachioji City, Japan) over a wavelength range of $200-260 \mathrm{~nm}$. Spectra were measured at a protein concentration of $0.1 \mathrm{mg} \mathrm{m}^{-1}$ in $10 \mathrm{mM}$ sodium acetate buffer, with a scan rate of $20 \mathrm{~nm} \mathrm{~min}{ }^{-1}$ and a band width of $1 \mathrm{~nm}$ using a $1 \mathrm{~mm}$ path-length quartz cuvette. A baseline spectrum obtained from $10 \mathrm{mM}$ sodium acetate buffer was subtracted from each protein scan. The quartz cuvette was rinsed with milli-Q grade water, $2 \%$ Hellmanex and sodium acetate buffer solutions in between each spectrum scan to prevent any contamination between solutions. Thermal unfolding was analysed between temperatures of 20 to $90^{\circ} \mathrm{C}$, maintained using a Peltier temperature control with a ramp rate of $1{ }^{\circ} \mathrm{C}$ per minute.

2.2.2. Surface tension. A Dynamic Contact Angle Meter and Tensiometer (DCAT21, Dataphysics instruments GmbH, Filderstadt) fitted with a du Nouy ring was used to measure the surface tension of G-CSF and PEG-GCSF solutions in $\mathrm{pH} 4$ acetate buffer. Protein solutions were individually prepared for all required concentrations prior to measurements commencing.

2.2.3. Dynamic light scattering. Dynamic light scattering (DLS) was used to assess protein size and aggregation in solution during thermal exposure. Aggregate growth of protein using DLS has previously correlated well to that measured using X-ray scattering. ${ }^{23}$ A Zetasizer Nano ZS (Malvern Instruments, U.K.) apparatus was equipped with a $4.0 \mathrm{~mW} \mathrm{He-Ne} \mathrm{laser} \mathrm{using}$ a backscattering configuration with detection at a scattering angle of $173^{\circ}$ using an avalanche photodiode. Temperature was increased from 25 to $65{ }^{\circ} \mathrm{C}$ in 1 degree increments. Freshly prepared solutions were filtered with a $0.22 \mu \mathrm{m}$ (Brand, 
Wertheim, Germany) membrane filter to remove any particulates. The particle diameter reported was $D_{50}$ determined from the volume based particle size distribution.

2.2.4. Isothermal titration calorimetry. Isothermal titration calorimetry (ITC) was performed with the VP-ITC microcalorimeter from Microcal $^{\mathrm{TM}}$, Inc (Northampton, MA, USA). The enthalpy of binding between polysorbate 20 and either GCSF or PEG-GCSF was determined using a multiple injection method to ensure accuracy of data. Prior to all titration experiments, all samples were degassed for 10 minutes (2 rounds) at $25{ }^{\circ} \mathrm{C}$. The sample cell and injection syringe were rinsed with freshly distilled Milli-Q grade water, and then rinsed again with the buffer solution that was used for preparation of the protein solutions (10 mM sodium acetate buffer). The reference cell was filled with degassed Milli-Q grade water and replaced prior to commencement of each experiment.

The binding stoichiometry measurements were controlled at a constant temperature of $25.0 \pm 0.02{ }^{\circ} \mathrm{C}$. The $1.4 \mathrm{ml}$ sample cell was filled with protein solution diluted to the desired concentration $\left(0.5 \mathrm{mg} \mathrm{ml}^{-1}\right)$ with $10 \mathrm{mM} \mathrm{pH} 4.0$ sodium acetate buffer prepared previously and the injection syringe (nominal volume $250 \mu \mathrm{l})$ was filled with polysorbate 20 solution $(1.5 \% \mathrm{w} / \mathrm{v})$. All titration experiments consisted of 25 injections of $10.0 \mu \mathrm{l}$ in 30 seconds with a spacing time of 300 seconds to allow appropriate time for temperature to equilibrate back to baseline. The initial delay for all experiments was set to 60 seconds with reference power and filter set to $10.0 \mu \mathrm{cal} \mathrm{s}{ }^{-1}$ (corresponding to $42 \mu \mathrm{J} \mathrm{s}^{-1}$ ) and 2 seconds, respectively. Stirring speed was set to 300 RPM (average revolution per minute) to ensure continuous mixing efficiency. The solution in the sample cell was continuously stirred while titrating $10 \mu \mathrm{L}$ of surfactant to prevent adsorbed layers of protein or surfactant being formed in the ITC experiment. ${ }^{24}$ A similar protocol was followed for the temperature study at 25,40 and $50{ }^{\circ} \mathrm{C}$, with a $0.1 \mathrm{mg} \mathrm{ml}^{-1}$ protein solution used.

Titration curves were analysed using Origin ${ }^{\circledR}$ software provided by Microcal, LLC. The data were corrected for the surfactant's heat of dilution by performing dilution of surfactant to buffer, to obtain only heat signatures that are associated with the surfactant-protein interaction. Data from the first injections were also discarded before fitting of data, due to abnormal results that may arise from a volumetric error caused by backlash in the motorized screw used to drive the syringe plunger. ${ }^{25}$

\section{Results and discussion}

\subsection{Bio-physical properties of G-CSF and the influence of PEGylation}

3.1.1. Protein secondary structure. Influence of PEGylation on the secondary structure of G-CSF was monitored using CD (Fig. 1(A)). Initially, for G-CSF, two minima at 222 and $208 \mathrm{~nm}$ were observed in the far UV spectra, typical of proteins with an alpha-helical structure and consistent with that expected for GCSF. ${ }^{26}$ It is evident that PEGylation of this G-CSF does not alter the alpha-helix structure; this is in agreement with a report by Natalello et al., ${ }^{13}$ and important in retaining the specific

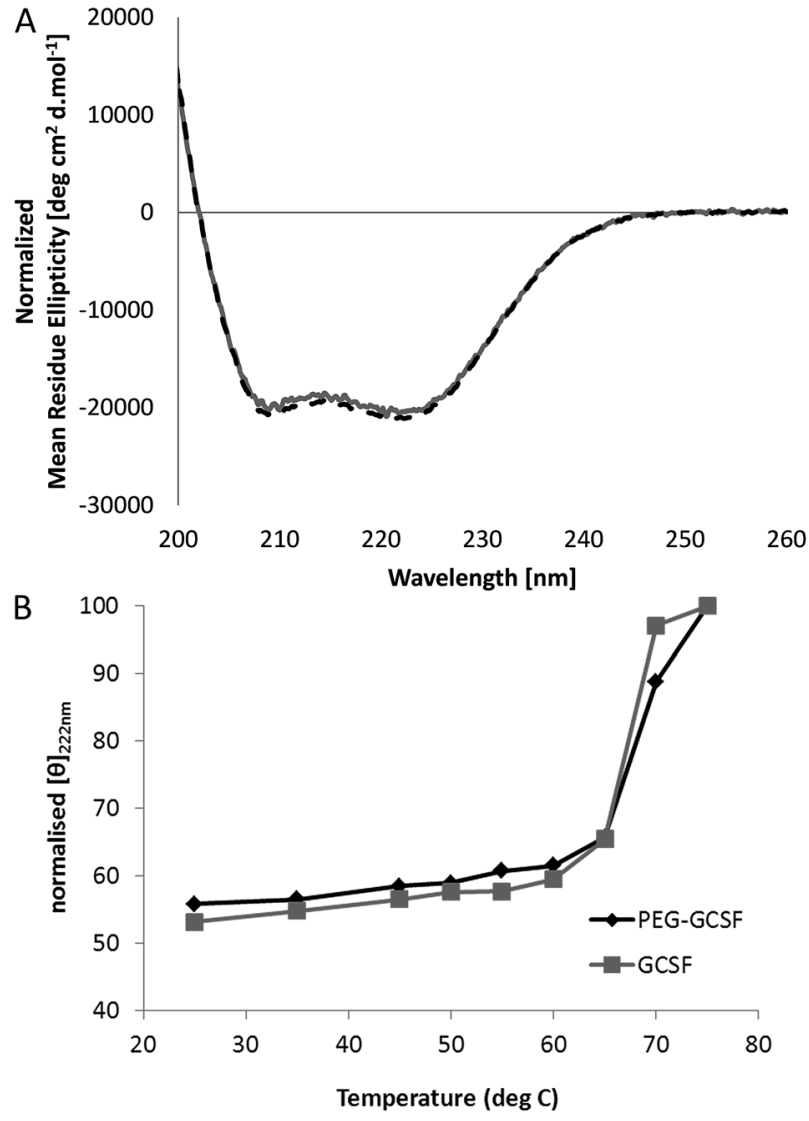

Fig. 1 (A) Influence of PEGylation on the CD spectrum of G-CSF at 25 ${ }^{\circ} \mathrm{C}$ (G-CSF: grey line; PEG-GCSF: black dashed line), and (B) monitoring the intensity of the circular dichroism spectra at $222 \mathrm{~nm}$ indicates the melting process for G-CSF and PEG-GCSF. All measured in $\mathrm{pH} 4$ acetate buffer.

function of the protein. To determine alterations to the protein secondary structure in terms of thermal stability, CD of G-CSF and PEG-GCSF was analysed as a function of temperature. Changes in the alpha-helical nature of G-CSF and PEG-GCSF were detailed by plotting the intensity at $222 \mathrm{~nm}$ versus temperature (Fig. 1(B)). These thermal unfolding experiments for G-CSF and PEG-GCSF follow a similar trend with increasing temperature and demonstrate that conformational changes associated with increased temperatures were not influenced by PEGylation. The "melting point" indicates when the protein secondary structure is lost, resulting in complete denaturation, and was indicated to be at about $67^{\circ} \mathrm{C}$ for both G-CSF and PEGGCSF. Therefore implying that attachment of PEG did not provide any protection from temperature induced conformational change. A previous FTIR study also concluded that conjugation of PEG did not alter secondary structural transitions of G-CSF induced by increasing temperature. ${ }^{\mathbf{1 4}}$

3.1.2. Interfacial adsorption. Activity of a protein at the airwater interface provides information on the amphiphilic nature of the molecule and indicates the extent of adsorption at this interface. Protein adsorption, both at the air-solution and solution-solid interfaces, has been proposed to be a source of protein aggregation in bio-pharmaceutical formulations. The 
interfacial activity of G-CSF and PEG-GCSF was evaluated using surface tension measurements as a function of protein concentration in $\mathrm{pH} 4$ acetate buffer (see Fig. 2). G-CSF was observed to be surface active, lowering the surface tension from $\sim 72 \mathrm{mN} \mathrm{m}^{-1}$ to $\sim 51 \mathrm{mN} \mathrm{m}^{-1}$ at concentrations greater than 8 $\mu \mathrm{M}$. This result is similar to that of Niven et al.,${ }^{27}$ who also found the air-water interface to be a source of aggregation for G-CSF. Interestingly, conjugation of PEG to G-CSF enhanced surface activity, as demonstrated by surface tension depression at lower concentrations than that observed for G-SCF, and a lower final plateau value in the surface tension of $\sim 46 \mathrm{mN} \mathrm{m}^{-1}$ at concentrations greater than $\sim 17 \mu \mathrm{M}$. This was contrary to expectation, as PEG is a hydrated chain and was hypothesized to reduce surface activity. However, other studies have reported greater adsorption of PEGylated proteins to hydrophobic interfaces compared to their native analogues. ${ }^{\mathbf{1 6 , 2 8}}$ In a study of lysozyme, despite the increase in molecular weight through conjugation of the PEG chain, PEGylated lysozyme was determined to adsorb faster at the air-water interface compared to the non-PEGylated parent protein. ${ }^{16}$ In addition, surface tension of PEG-GCSF solutions exhibited two steps as a function of concentration (Fig. 2), which may arise from a change in the molecular orientation at the interface, or a concentration dependent aggregation behaviour occurring at the air-water interface. Protein adsorption at the air-water interface is a complex combination of adsorption, aggregation, and orientational and structural re-organisation. A change in adsorbed PEG-GCSF orientation at the air/water interface with the PEG chain extending into solution would decrease the likelihood of association with proteins present in the sub-layer. While for GSCF, association with protein molecules in the sub-layer may compromise its association with the interface, leading to a less pronounced surface tension depression, as was observed (Fig. 2). Surface tension reduction suggests the protein molecules to be amphiphilic in nature, and PEGylation extenuates this. Thus, both molecules contain exposed hydrophobic regions, providing a potential source for aggregation in solution.

3.1.3. Protein aggregation initiated via temperature elevation. Thermal induced protein aggregation is known to occur as a result of protein unfolding and exposure of hydrophobic

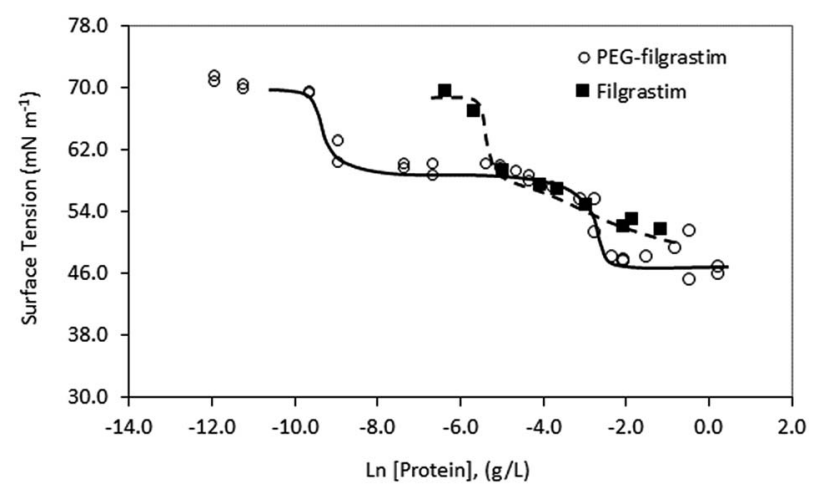

Fig. 2 Surface tension of G-CSF and PEG-GCSF solutions as a function of concentration, in $\mathrm{pH} 4$ acetate buffer. moieties leading to association between molecules. As illustrated in DLS studies as a function of temperature (Fig. 3), GCSF was observed to irreversibly aggregate in solution at temperatures less than $55{ }^{\circ} \mathrm{C}$, which is below the denaturation temperature obtained from CD melting curves of $67^{\circ} \mathrm{C}$. Further, the exact temperature of aggregation was inversely dependent on G-CSF concentration (Fig. 3), i.e. as concentration increased from 0.5 to $3.5 \mathrm{mg} \mathrm{l}^{-1}$, the aggregation temperature decreased from $55{ }^{\circ} \mathrm{C}$ to $\sim 42{ }^{\circ} \mathrm{C}$. This concentration dependent thermal aggregation behaviour has been reported previously in studies of $\mathrm{MAbs}^{29,30}$ and attributed to increased probability of interaction between the MAbs leading to increased self-association. In addition, Raso et al., ${ }^{26}$ described a concentration dependent rate of aggregation for G-CSF at $37{ }^{\circ} \mathrm{C}$ from a subtly altered conformation, not too different from the native state. Thermal induced aggregation of PEG-GCSF was evident from approximately $55{ }^{\circ} \mathrm{C}$. Significantly, a reduced concentration dependency was observed compared to the unmodified G-CSF. While experiments performed here extended for a few hours, Treuheit et al. ${ }^{22}$ reported a concentration dependent aggregation for PEG-GCSF solutions kept at $37{ }^{\circ} \mathrm{C}$ over a 12 week period, indicating that PEG-GCSF did undergo increased aggregation as concentration increased. Thus, while PEGylation did not provide protection from thermal induced denaturation, it did increase the onset temperature of subsequent aggregation.

Irrespective of PEGylation, both proteins demonstrated aggregation at temperatures below that of the denaturation temperature measured with CD. The melting temperature determined from CD represents a global structural transformation within proteins and does not provide information on smaller conformational changes that may be taking place at temperatures less than the melting point. Other techniques have also suggested the 3-dimensional structure of G-CSF to undergo conformational changes at temperatures lower than required for denaturation. In a study by Rajan et al.,${ }^{14}$ increasing conformational transition from alpha-helix to $\beta$-sheet structure

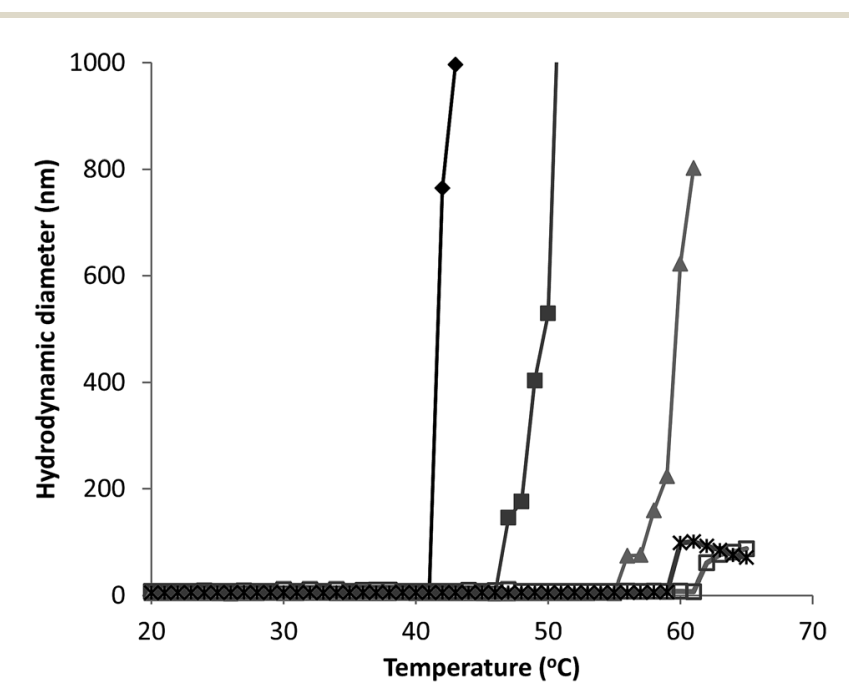

Fig. 3 Hydrodynamic diameter as a function of temperature for G$\operatorname{CSF}\left(0.5(\Delta), 1.5(\square)\right.$ and $\left.3.5(\diamond) \mathrm{mg} \mathrm{mL}^{-1}\right)$ and PEG-GCSF $(1(\square)$ and $5(*)$ $\mathrm{mg} \mathrm{mL}^{-1}$ ) in $10 \mathrm{mM}$ acetate buffer at $\mathrm{pH} 4$. 
was observed for both G-CSF and PEG-GCSF with increasing temperature using second-derivative FTIR. In addition, a recent time-of-flight secondary ion mass spectrometry (ToF-SIMS) study that investigated conformational aspects of adsorbed GCSF as a function of temperature, detailed continuous changes to the 3-dimensional structure as temperature increased from 25 to $55{ }^{\circ} \mathrm{C}^{31}$ Amino acid residues of tyrosine, methionine and phenylalanine, all of which contain hydrophobic functional groups, were found to contribute to the observed structural change and provided evidence for exposure of hydrophobic moieties of G-CSF at temperatures as low as 35 ${ }^{\circ} \mathrm{C}$. All of these observations are consistent with exposure of hydrophobic amino acid sequences of G-CSF at temperatures below that required for macroscopic denaturation, which would allow for greater association between protein molecules leading to aggregation, as detected here using dynamic light scattering.

Significantly, PEGylation of G-CSF modified the extent of aggregation, greatly hindering aggregate growth. While G-CSF demonstrated continually growing aggregates to sizes greater than $2 \mu \mathrm{m}$, PEG-GCSF aggregates remained at sizes less than $120 \mathrm{~nm}$. This confirms the work by Rajan et al. ${ }^{\mathbf{1 4}}$ where conjugation of PEG to G-CSF was found to reduce the size of aggregates, and in a study of lysozyme, PEGylation was found to reduce the formation of lysozyme particles by half. ${ }^{16}$ Therefore, while PEGylation did not alter conformational changes with increased temperature, it did infer stability against thermal induced aggregation, suggesting protection of exposed hydrophobic regions by the hydrated PEG chain. This aspect is significant; while PEGylation could not protect the protein from denaturation with increasing temperature, it has been shown to limit aggregation to only a few protein molecules, which is beneficial from a therapeutic formulation aspect, in limiting the growth size of protein aggregates.

\subsection{Surfactant interactions and G-CSF stability}

Despite evidence for increased stability against aggregation, commercial PEGylated therapeutic proteins continue to be formulated using non-ionic surfactants, similarly to their nonPEGylated analogues. With few studies examining interactions and stability of non-ionic surfactant/PEGylated protein formulations, it is therefore interesting to investigate the effect of PEGylation on the role and interactions of non-ionic surfactants in protein formulations. From surface tension measurements discussed earlier (Fig. 2), both G-CSF and PEG-GCSF are amphiphilic, with the presence of hydrophobic regions providing potential sites for both self-association and interaction with hydrocarbon chains of surfactant molecules. In this section, the influence of non-ionic surfactant, polysorbate 20 , on the structural and physical stability of G-CSF and PEG-GCSF in solution will be explored.

3.2.1. Protein-surfactant interaction. Firstly, the mechanism of interaction between polysorbate 20 and the proteins was investigated using ITC. For G-CSF, 1.5\% (w/v) polysorbate 20 was titrated into $0.5 \mathrm{mg} \mathrm{ml}^{-1}$ of the protein (Fig. $4 \mathrm{~A}$ ). Each injection resulted in an exothermic event, which decreased in magnitude as the experiment proceeded. Initially upon injection of polysorbate 20 to a solution of G-CSF or PEG-GCSF, the

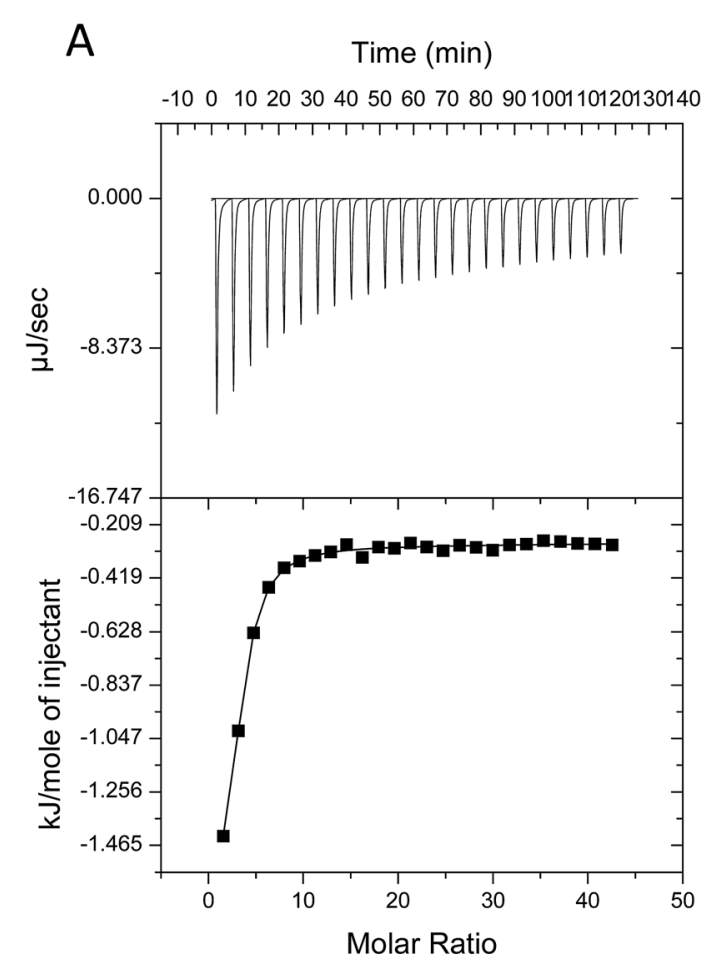

B

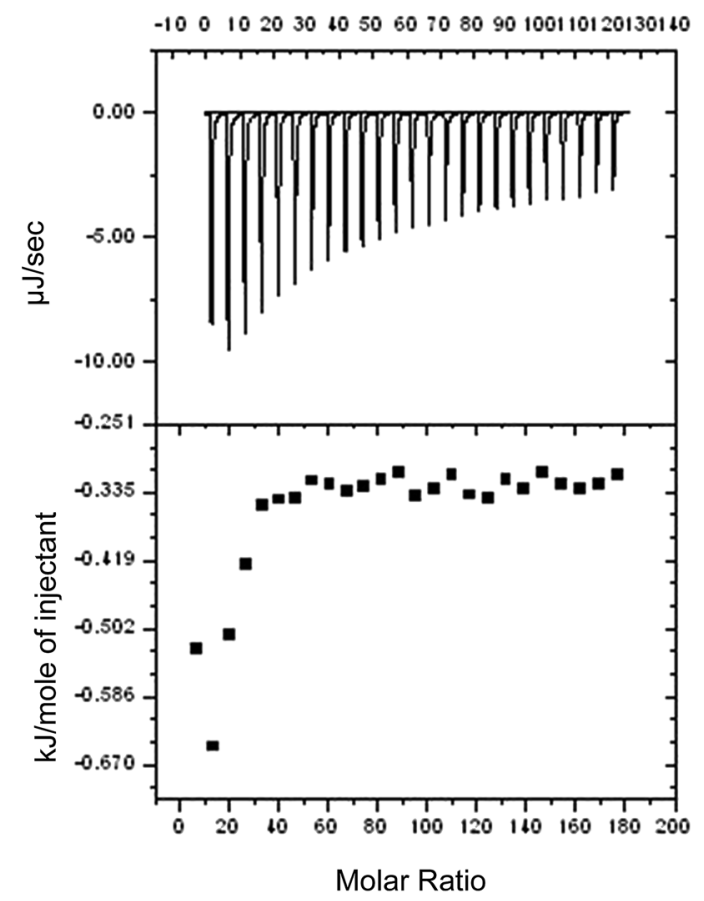

Fig. 4 Experimental power flow signals (top), and associated binding isotherms (bottom) for the calorimetric titrations of polysorbate 20 to 0.5 $\mathrm{mg} \mathrm{ml}^{-1}$ G-CSF (A) and $0.5 \mathrm{mg} \mathrm{ml}^{-1}$ PEG-GCSF (B). Thermograms were corrected for surfactant heat of dilution associated with each polysorbate 20 injection. Solutions were prepared and diluted in $10 \mathrm{mM}$ sodium acetate buffer. 
cumulative heat energy produced with each injection is associated with the binding of surfactant to the protein, as well as surfactant dilution. However, upon injection of polysorbate 20 concentration above the CMC, additional enthalpy of injection $\left(\Delta H_{\text {dil }}\right)$, resulting from the dilution of the surfactant are observed which can be influenced by two phenomena; enthalpy of demicellization of polysorbate 20 and enthalpy of dilution of polysorbate 20 monomers. Separate experiments of polysorbate 20 titrated into buffer were used to correct for the heat of dilution and de-micellisation of polysorbate 20 , which may interfere with fitting of the data; corrected thermograms are displayed in Fig. 4.

All titration experiments lead to a low change heat and this was exothermic in nature. Multiple titration experiments were performed prior to obtaining the final results as shown in Fig. 4, with different concentration of both polysorbate 20 and proteins in 10 and $200 \mathrm{mM}$ sodium acetate buffer. All resulted in similar thermograms that are characterized by low binding heats that are not representative of typical binding curves due to the absence of a baseline at low polysorbate to protein ratios. This suggests that only a fraction of polysorbate 20 monomers bind to G-CSF and that the binding is weak. However, calculation of the binding enthalpy $(\Delta H)$ and binding affinity $(K)$ from the titration data of polysorbate 20 to both G-CSF and PEGGCSF was attempted, with a two site kinetic model consistently providing the best fit (Table 1). The data were fitted with the assumption that the binding of polysorbate 20 to both proteins occur at multiple sites, with two sets of binding affinities indicating binding occurred with two different states (surfactant monomers and aggregates). The observation that polysorbate 20 interacts with G-CSF in two different mechanisms is supported by research measuring the kinetics of surface tension depression by mixed polysorbate/G-CSF solutions, ${ }^{32}$ where it was concluded that G-CSF associated with both surfactant aggregates and individual molecules.

Polysorbate 20 has also shown to exhibit similar binding behaviour producing two different binding affinities with other proteins, such as to albutropin. ${ }^{4}$ Albutropin is a novel form of human Growth Hormone (hGH), genetically fused with human serum albumin (HSA) with 6 alpha-helical structures in each domain..$^{33}$ Previous studies have also demonstrated similar surfactant binding behaviour such as the interaction of sodium dodecyl sulfate (SDS) to bovine serum albumin (BSA), showing two classes of SDS binding sites. ${ }^{34}$ Salmaso et al. ${ }^{35}$ also concluded the binding of G-CSF with PEG-cholane (an

Table 1 Summary of binding stoichiometry using a two site binding model for titration of polysorbate 20 into $0.5 \mathrm{mg} \mathrm{ml}^{-1} \mathrm{GCSF}$ and PEGGCSF, in $10 \mathrm{mM}$ acetate at $\mathrm{pH} 4$

\begin{tabular}{|c|c|c|c|c|}
\hline \multirow[b]{2}{*}{ Protein } & \multicolumn{2}{|c|}{$\begin{array}{l}\text { Binding constant } K_{\mathrm{a}} \\
\left(\mathrm{M}^{-1}\right)\end{array}$} & \multicolumn{2}{|c|}{$\begin{array}{l}\text { Enthalpy } \Delta H \\
\left(\mathrm{~kJ} \mathrm{~mol}^{-1}\right)\end{array}$} \\
\hline & $1 \mathrm{st}$ & 2nd & 1st & 2nd \\
\hline G-CSF & $4.4 \times 10^{5}$ & 3.0 & -4.6 & -0.3 \\
\hline PEG-GCSF & $1.2 \times 10^{4}$ & 23.8 & 12.8 & -66.4 \\
\hline
\end{tabular}

amphiphilic compound) was multi modal in nature, with a two site binding model providing the best fit to the ITC data.

Interaction of polysorbate 20 with PEG-GCSF was similarly studied with ITC (Fig. 4B). As a result of protein concentration limitations, data were difficult to obtain, and similarly to G-CSF lacked a baseline at low polysorbate 20 to PEG-GCSF ratios. However, the form of the isotherm was best fitted with a two site model, similar to that of G-CSF and suggest the interaction behaviour between polysorbate 20 and G-CSF is similar, irrespective of PEGylation. A recent study investigating PEGylated lysozyme also concluded that PEGylation had little impact on the nature of interaction of lysozyme with excipients such as sucrose and guanidine hydrochloride. ${ }^{36}$ The isotherm for PEGGCSF suggests the interaction to be even weaker than that observed with G-CSF, with low binding affinities determined (Table 1). Intuitively, a structural interference to any interaction of polysorbate 20 with the PEG-GCSF molecule would be inferred by the presence of the $20 \mathrm{kDa}$ PEG chain attached to the protein.

Binding isotherms for the interaction of polysorbate 20 to 0.1 $\mathrm{mg} \mathrm{ml}^{-1}$ solutions of G-CSF and PEG-GCSF were measured by ITC between temperatures of 25 and 55 degrees (Fig. 5), below the onset of thermal denaturation measured by CD. With increased temperature, it can be seen for both systems that there was a decrease in the reaction enthalpy from $25^{\circ} \mathrm{C}$ to $40^{\circ} \mathrm{C}$ (Fig. 5). The decrease in enthalpy observed was similar to that observed by Hoffmann et al., ${ }^{37}$ and was associated with an entropic effect reducing the protein-surfactant interaction. However at $55^{\circ} \mathrm{C}$, both proteins showed an increase in negative reaction enthalpy, indicating an increase in surfactant-protein binding. This may have occurred as a result of expansion of the proteins native conformation exposing hydrophobic regions of the protein as discussed earlier and in Kempson et al. ${ }^{31}$ for increased binding of the hydrophobic surfactant chains. This provides further evidence for polysorbate 20 interaction with GCSF via a hydrophobic mechanism.

3.2.2. Protein secondary structure in the presence of surfactant. To establish whether the presence of polysorbate 20 altered the secondary structure of G-CSF and PEG-GCSF, CD of the protein was determined with addition of increasing concentration of polysorbate 20 (Fig. 6). The minima in the ellipticities at 208 and $222 \mathrm{~nm}$ remained for all concentrations of polysorbate 20; even at concentrations of polysorbate 20 up to 100 times the CMC $\left(0.007 \%(\mathrm{w} / \mathrm{v})^{6}\right)$, both proteins retained a strong alpha-helical character, evidence that polysorbate 20 does not interact with G-CSF in a manner that leads to destabilisation through denaturation of the proteins. There was no change in the peak positions, suggesting an insignificant role of hydrogen bonding. ${ }^{38}$ The ratio, $R$, of the molar ellipticities at 222 and $208 \mathrm{~nm}\left(\theta_{222} / \theta_{208}\right)$ has been used as an approximate gauge of $\alpha$-helicity. Values for $R$ range from 1.04 to 1.01 for GCSF and G-CSF with polysorbate 20 up to a ratio of $1: 100$, and only at high concentrations of surfactant (G-CSF to polysorbate 20 of $1: 1000$ ) does the ratio show a deviation from 1 , with a value of 0.93 , suggesting that the secondary structure of G-CSF slightly decreased at high surfactant concentrations $(0.65$ wt $\%$ polysorbate 20). PEGylated G-CSF shows a similar trend 

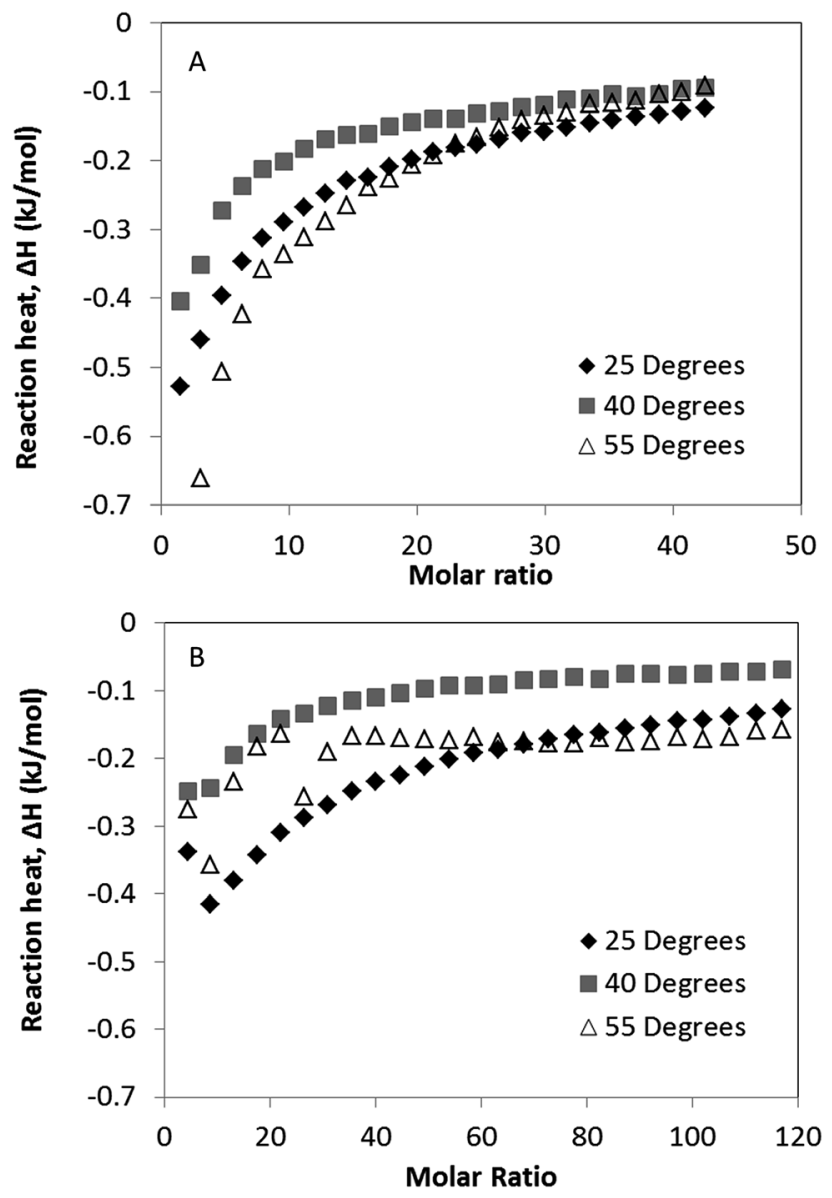

Fig. 5 Binding isotherms of polysorbate-20 to both G-CSF (A) and PEG-GCSF (B) between $25{ }^{\circ} \mathrm{C}$ and $55^{\circ} \mathrm{C}$. Each point represents the amount of heat released by the protein-surfactant interaction with each titration of polysorbate-20 into the reaction vessel containing $1.43 \mathrm{ml}$ of the protein solution.

with $R$ values between 1.02 and 1.05 for PEG-GCSF at surfactant ratios $\leq 1: 50$, and decreasing to 0.94 , only at the highest concentration measured $(0.65 \mathrm{wt} \%)$, implying that the presence of the PEG chain appended to G-CSF did not alter the structural behaviour of G-CSF initiated by polysorbate 20 .

The $\theta_{222} / \theta_{208}$ ratio $(R)$ has also been used to distinguish coiled-coils from single stranded alpha helices. Zhou et al. ${ }^{39}$ determined empirically that $R$ is equal or higher than 1 for twostranded coiled-coils, and is lower than 1 (between 0.8 and 0.9) for non-interacting helices. In this study, the $\theta_{222} / \theta_{208}$ ratios ranging from 1.01 to 1.05 for G-CSF and PEG-GCSF both alone and in the presence of polysorbate 20 up to concentrations of $0.065 \mathrm{wt} \%$, indicate that the helices of the proteins are associated together in coiled-coils and this 3-dimensional association is not influenced by concentrations of polysorbate 20 up to $0.065 \mathrm{wt} \%$.

3.2.3. Influence of non-ionic surfactant on protein aggregation. The influence of polysorbate 20 concentration on thermal induced aggregation of G-CSF and PEG-GCSF was monitored using dynamic light scattering (Fig. 7). For G-CSF, it was consistently observed that concentrations lower than the

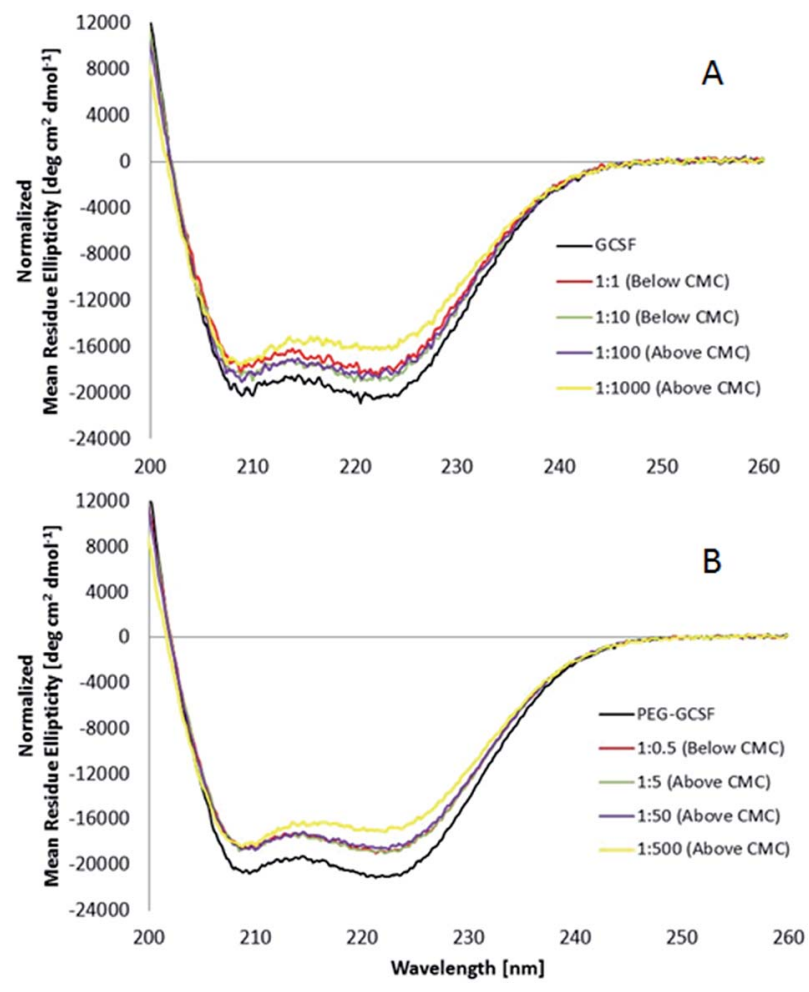

Fig. 6 Influence of polysorbate-20 on the circular dichroism spectrum of (A) G-CSF and (B) PEG-GCSF incubated at $25^{\circ} \mathrm{C}$ for 12 hours in presence of various concentrations of polysorbate-20, below and above the critical micelle concentration (CMC). Concentrations shown are molar ratio of protein to surfactant concentration.

CMC resulted in a subtle increase in the temperature of aggregation and concentrations greater than the CMC led to a decrease in the temperature of aggregation. For PEG-GCSF, polysorbate 20 did not influence the temperature of aggregation at low concentrations, but at concentrations in excess of the CMC, appeared to limit aggregation to only a few molecules in each aggregate. For PEG-GCSF, Treuheit et al., ${ }^{22}$ observed that greater aggregation of PEG-GCSF occurred as the concentration of polysorbate 20 increased up to $0.01 \%$ for solutions incubated at $29{ }^{\circ} \mathrm{C}$ for 59 weeks. Thus, while polysorbate 20 did not impact greatly on the protein aggregation due to increased temperatures measured here, it may still play a role in interface or agitation induced aggregation, which was outside the scope of the current study.

Commercially, protein therapeutics are formulated with protein concentrations of 600 to $1000 \mu \mathrm{g} \mathrm{ml}^{-1}$ and $10 \mathrm{mg} \mathrm{ml}^{-1}$, respectively for G-CSF and PEG-GCSF. ${ }^{40}$ Included in the formulation, a concentration of 0.0033 to 0.004 wt $\%$ polysorbate 20 is typically used, which is below the cmc $(0.007 \mathrm{wt} \%)$. This represents approximately one surfactant molecule for every protein molecule for G-CSF, and for PEG-GCSF approximately one surfactant molecule for every ten protein molecules. When combined with the ITC and CD results reported here, it appears that polysorbate 20 interaction with GCSF is weak, does not effect a change in the protein structure that would lead to denaturation, and due to the low ratio of surfactant to protein 

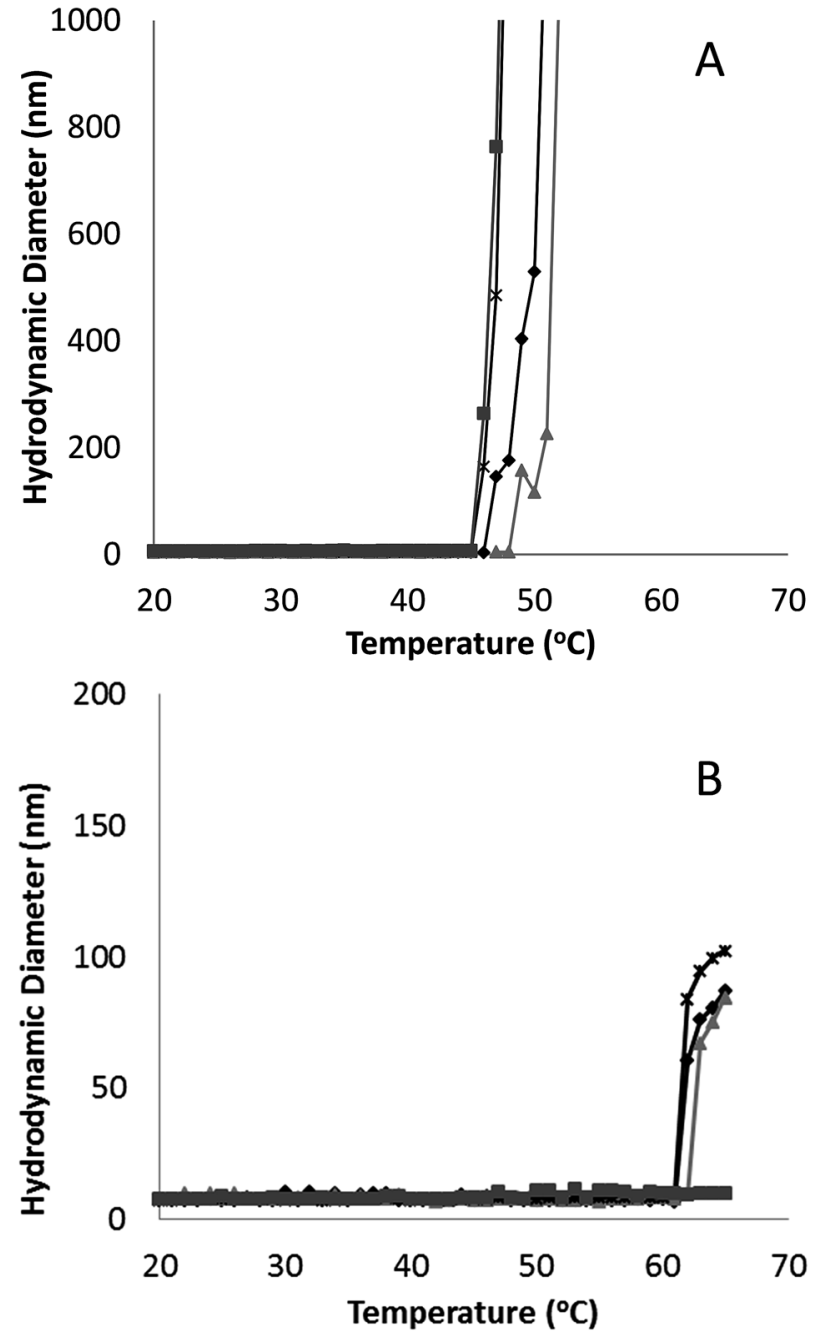

Fig. 7 Influence of polysorbate 20 concentration on protein aggregation as a function of increasing temperature for (A) G-CSF $(1.5 \mathrm{mg}$ $\mathrm{ml}^{-1}$ ) and (B) PEG-GCSF $\left(1 \mathrm{mg} \mathrm{ml}^{-1}\right)$ in $10 \mathrm{mM}$ acetate buffer at $\mathrm{pH} 4$. The ratio of protein : surfactant are as follows; $(A)$ without polysorbate $20(\diamond), 1: 0.6(\Delta), 1: 6(*), 1: 60(\square)$ and $(B)$ without polysorbate $20(\diamond)$, $1: 2(\Lambda), 1: 20(*)$, and $1: 200(\square)$.

molecules is possibly transient. PEGylation of GCSF was not found to have influenced the mechanism of aggregation or interaction with polysorbate 20, however did significantly minimise growth in the thermally induced aggregate size, and therefore represents a more physically stable formulation.

\section{Conclusion}

PEGylation of G-CSF did not alter the three dimensional alpha helical structure or observed temperature of denaturation of the protein. PEGylation of G-CSF did increase the amphiphilic nature, with PEG-GCSF showing greater activity at the buffer-air interface. Both G-CSF and PEG-GCSF demonstrated thermally induced aggregation at temperatures below that of denaturation, and for G-CSF an inverse relationship was observed between concentration and the temperature at which thermal induced aggregation occurred. However, PEGylation did infer significant stability against thermal induced aggregation in solution, increasing the temperature at which aggregation was first observed to approximately $58^{\circ} \mathrm{C}$, from as low as $43^{\circ} \mathrm{C}$ for $\mathrm{G}$ $\mathrm{CSF}$, depending on concentration. Conjugation of PEG to G-CSF was shown to limit the thermal induced protein aggregation to a maximum aggregate size of less than $120 \mathrm{~nm}$ in diameter, compared to aggregates of greater than $2 \mu \mathrm{m}$ for G-CSF.

In terms of non-ionic surfactant interaction with the proteins, polysorbate 20 did not disturb the alpha helical nature of G-CSF, independent of PEGylation. Direct binding between polysorbate 20 and G-CSF appears to be weak, and to occur through two different mechanisms; one involving individual surfactant molecules and another involving surfactant aggregates. Despite the presence of a hydrated PEG chain, similar binding behaviour was observed between PEG-GCSF and polysorbate 20. These findings increase understanding of stability and interactions in therapeutic protein preparations and may enable more intelligent formulation design.

\section{Acknowledgements}

Hopsira Inc. Adelaide is gratefully acknowledged for supplying the G-CSF and PEG-GCSF, for financial support and fruitful discussions.

\section{References}

1 H. J. Lee, A. McAuley, K. F. Schilke and J. McGuire, Adv. Drug Delivery Rev., 2011, 63, 1160-1171.

2 D. S. Pisal, M. P. Kosloski and S. V. Balu-Iyer, J. Pharm. Sci., 2010, 99, 2557-2575.

3 N. B. Bam, J. L. Cleland, J. Yang, M. C. Manning, J. F. Carpenter, R. F. Kelley and T. W. Randolph, J. Pharm. Sci., 1998, 87, 1554-1559.

4 D. K. Chou, R. Krishnamurthy, T. Randolph, J. F. Carpenter and M. C. Manning, J. Pharm. Sci., 2005, 94, 1368-1381.

5 T. Arakawa and Y. Kita, J. Pharm. Sci., 2000, 89, 646.

6 S. Deechongkit, J. Wen, L. O. Narhi, Y. Jiang, S. S. Park, J. Kim and B. A. Kerwin, J. Pharm. Sci., 2009, 98, 3200-3217.

7 D. Otzen, Biochim. Biophys. Acta, Proteins Proteomics, 2011, 1814, 562.

8 N. B. Bam, T. W. Randolph and J. L. Cleland, Pharm. Res., 1995, 12, 2-11.

9 T. W. Randolf and L. S. Jones, in Pharm. Biotechnol., ed. C. J. F. and M. M. C., Kluwer Academic/Plenum Publishers, NewYork, 2002, vol. 13, pp. 159-175.

10 A. Abuchowski, J. R. McCoy, N. C. Palczuk, T. van Es and F. F. Davis, J. Biol. Chem., 1977, 252, 3582.

11 G. Molineux, Cancer Treat. Rev., 2002, 28, 13.

12 B. Plesner, C. J. Fee, P. Westh and A. D. Nielson, Eur. J. Pharm. Biopharm., 2011, 79, 399-405.

13 A. Natalello, D. Ami, M. Collini, L. D'Alfons, G. Chirico, G. Tonon, S. Scaramuzza, R. Schrepfer and S. M. Doglia, PLoS One, 2012, 7, e42511.

14 R. S. Rajan, T. Li, M. Aras, C. Sloey, W. Sutherland, H. Arai, R. Briddell, O. Kinstler, A. M. K. Lueras, Y. Zhang, 
H. Yeghnazar, M. Treuheit and D. N. Brems, Protein Sci., 2006, 15, 1063-1075.

15 A. Grigoletto, A. Mero, I. Zanusso, O. Schiavon and G. Pasut, Macromol. Biosci., 2016, 16, 50-60.

16 L. S. Holm, A. Mcumber, J. E. Rasmussen, M. Obiols-Rabasa, P. W. Thulstrup, M. R. Kasimova, T. W. Randolph and M. van de Weert, J. Pharm. Sci., 2014, 103, 3043-3054.

17 G. D. Demetri and J. D. Griffin, Blood, 1991, 78, 2791.

18 D. Metcalf, Blood, 1986, 67, 257-267.

19 I. A. Tabbara, South. Med. J., 1993, 86, 350.

20 K. Yamazaki, T. Iwura, K. Murayama, R. Ishikawa and Y. Ozaki, Vib. Spectrosc., 2005, 38, 33-38.

21 T. C. Souza, T. C. Boone, J. Gabrilove, P. H. Lai, K. M. Zsebo, D. C. Murdock, V. R. Chazin, J. Bruszewski, H. Lu and K. K. Chen, Science, 1986, 232, 61-65.

22 M. J. Treuheit, A. A. Kosky and D. N. Brems, Pharm. Res., 2002, 19, 511-516.

23 J. W. Regini, H. Ecroyd, S. Meehan, K. Bremmell, M. J. Clarke, D. Lammie, T. Wess and J. A. Carver, Mol. Vision, 2010, 16, 2446-2456.

24 M. M. Pierce, C. Raman and B. T. Nall, Methods, 1999, 19, 213-221.

25 L. S. Mizoue and J. Tellinghuisen, Anal. Biochem., 2004, 326, 125-127.

26 S. W. Raso, J. Abel, J. M. Barnes, K. M. Maloney, G. Pipes, M. J. Treuheit, J. King and D. N. Brems, Protein Sci., 2005, 14, 2246-2257.

27 R. W. Niven, S. J. Prestrelski, M. J. Treuheit, A. Y. Ip and T. Arakawa, Int. J. Pharm., 1996, 127, 191-201.
28 C. Pinholt, J. T. Bukrinsky, S. Hostrup, S. Frokjaer, W. Norde and L. Jorgensen, Eur. J. Pharm. Biopharm., 2011, 77, 139147.

29 F. He, S. Hogan, R. F. Latypov, L. O. Narhi and V. I. Razinkov, J. Pharm. Sci., 2010, 99, 1707-1720.

30 T. Menzen and W. Friess, J. Pharm. Sci., 2013, 102, 415-428.

31 I. M. Kempson, P. Chang, K. Bremmell and C. A. Prestidge, Langmuir, 2013, 29, 15573-15578.

32 H. L. Kim, A. McAuley and J. McGuire, J. Pharm. Sci., 2014, $103,1337$.

33 B. L. Osborn, L. Sekut, M. Corcoran, C. Poortman, B. Sturm, G. Chen, D. Mather, H. L. Lin and T. J. Parry, Eur. J. Pharmacol., 2002, 456, 149-158.

34 A. D. Nielsen, K. Borch and P. Westh, Biochim. Biophys. Acta, Protein Struct. Mol. Enzymol., 2000, 1479, 321-331.

35 S. Salmaso, S. Bersani, F. Mastrotto, G. Tonon, R. Schrepfer, S. Genovese and P. Caliceti, J. Controlled Release, 2012, 162, 176-184.

36 L. S. Holm, P. W. Thulstrup, M. R. Kasimova and M. van de Weert, PLoS One, 2015, 10, e0133584.

37 C. Hoffmann, A. Blume, I. Miller and P. Garidel, Eur. Biophys. J., 2009, 38, 557-568.

38 T. S. Banipal, A. Kaur, I. A. Khan and P. K. Banipal, RSC Adv., 2016, 6, 34754-34769.

39 N. E. Zhou, C. M. Kay and R. S. Hodges, J. Biol. Chem., 1992, 267, 2664-2670.

40 MIMS Australia, MIMs Online, 2016. 